\title{
A UTILIZAÇÃO DE TECNOLOGIAS DE SUPORTE AO ENSINO A DISTÂNCIA: PERSPETIVAS DOS PROFESSORES
}

\author{
Teresa Jesus Santos \\ Universidade do Minho, Portugal \\ tjcps@sapo.pt
}

Recepción Artículo: 12 mayo 2021

Admisión Evaluación: 12 mayo 2021

Informe Evaluador 1: 17 mayo 2021

Informe Evaluador 2: 21 mayo 2021

Aprobación Publicación: 01 junio 2021

\section{RESUMO}

Tendo presente o isolamento social provocada pela pandemia covid 19, ensinar e aprender só foi possível, através do formato ensino a distância, utilizando os computadores, smarphones, tablets, televisão, internet e plataformas digitais. 0 ensino presencial foi substituído pela modalidade de ensino a distância, obrigando as escolas a repensarem novos modos de organização curricular, pedagógica e administrativa, com o objetivo de poderem dar continuidade ao processo de ensino e de aprendizagem, junto de todos os alunos. Neste artigo, apresentamos os resultados de um estudo que teve como objetivo principal conhecer as perspetivas de professores da educação préescolar e do 1. ciclo do ensino básico, sobre como foram monitorizadas e avaliadas as aprendizagens, durante a educação a distância. Para isso, foram realizados dois inquéritos por questionário, um para os professores da educação pré-escolar e outro para os professores do $1 . .$. ciclo do ensino básico. Os dados foram recolhidos, através da plataforma Google forms, junto de $(n=245)$ professores dos mesmos níveis de ensino e utilizamos o tratamento estatístico descritivo e inferencial, usando-se o software SPSS para a sua análise. Os resultados apontam que a maioria dos profesores: i) recorreram, ao manual adopado, vídeos, jogos, fichas e às plataformas digitais (facebook, whatsap, classroom, );ii) comunicou regularmente e acompanhou os alunos em todo o processo do ensino a distância com exceção dos alunos com ausência de recursos educativos a nível das Tecnologias Informação e Comunicação (digitais). Na avaliação as evidências avaliativas foram diversificada desde 0 trabalho individual; fichas; questionários; fotos; vídeos; portefólio; Ensaio/composições /reflexão crítica e outros. Os professores e alunos adaptaram-se a metodologias de trabalho, para mediar o ensino e aprendizagem, através do desenvolvimento de competências digitais.

Palabras clave: ensino a distância; adaptação; recursos educativos digitais; Covid-19; professores 


\title{
A UTILIZAÇÃO DE TECNOLOGIAS DE SUPORTE AO ENSINO A DISTÂNCIA: PERSPETIVAS dOS PROFESSORES
}

\begin{abstract}
The use of technologies to support distance education: perspectives of teachers. Bearing in mind the social isolation caused by the covid pandemic 19, teaching and learning was only possible, through the distance learning format, using computers, smartphones, tablets, television, internet and digital platforms. Face-to-face teaching has been replaced by distance learning, forcing schools to rethink new ways of curricular, pedagogical and administrative organization, with the aim of being able to continue the teaching and learning process with all students. In this article, we present the results of a study that had as main objective to know the perspectives of teachers of pre-school education and of the 1st cycle of basic education, on how learning was monitored and evaluated during distance education. For this, two surveys were carried out by questionnaire, one for teachers of pre-school education and another for teachers of the 1st cycle of basic education. The data were collected, through the Google forms platform, from $(n=245)$ teachers from the same educational levels and we used the descriptive and inferential statistical treatment, using the SPSS software for their analysis. The results show that the majority of teachers: i) used videos, games, records and digital platforms (facebook, whatsap, classroom,) to the adopted manual; ii) communicated regularly and accompanied students throughout the teaching process. distance with the exception of students with no educational resources at the level of Information and Communication Technologies (digital). In the evaluation, the evaluative evidence was diversified since the individual work; files; questionnaires; Photos; videos; portfolio; Essay / compositions / critical reflection and others. Teachers and students adapted to work methodologies, to mediate teaching and learning, through the development of digital skills.
\end{abstract}

Keywords: distance learning; adaptation; digital educational resources; Covid-19; teachers

\section{INTRODUÇÃO}

0 ensino a distância surgiu como uma oferta educativa e formativa para dar resposta às crianças e jovens que, pelos mais diferentes motivos, se encontram em situações, de caráter temporário ou permanente, que as impedem de frequentar regularmente uma escola e, por consequência, estão sujeitas a descontinuidade na sua aprendizagem, o que conduz ao insucesso e ao abandono escolares antes da conclusão da escolaridade obrigatória.

Contudo, a situação de emergência e obrigatório isolamento social, recomendado pelos órgãos de saúde pública levou, a 12 de março de 2020, o Primeiro-Ministro português a anunciar o encerramento de todas as escolas do país, a partir do dia 16 do mesmo mês, para tentar conter a propagação do surto de Covid-19, tendo estabelecido, um mês depois, as medidas excecionais e temporárias para o funcionamento do ensino a distância para todos.

Sem tempo para preparação e com vocabulário estranho, a pandemia, "expulsou os alunos da sala" e das escolas, não deixando outra alternativa que não o ensino online, (Palmeirao, 2020). De um dia para o outro, as escolas fecharam por imposição, podendo afirmar-se que "os sistemas educativos europeus não tinham sido afetados tão negativamente desde a II Guerra Mundial" (Costa, 2020). 0 Ministério da Educação produziu recursos, orientações, colheu práticas, estabeleceu parcerias, para apoiar o trabalho às escolas e aos professores. Por seu lado, os professores deram uma resposta de emergência, alteraram métodos e implementaram novas formas de avaliação (Costa, 2021). A este propósito, Figueiredo (2020) refere que os professores começaram de imediato a discutir soluções nas redes sociais. Criaram no Facebook, por iniciativa própria, o grupo "E-learning Apoio", dedicado à ajuda entre professores. Três meses depois, esse grupo registava quase 30 mil membros e uma atividade intensiva e ininterrupta de entreajuda entre professores. (2020, p. 3). Na perspetiva de Verdasca (2021) "a inovação tornou-se atributo e fonte de energia perante as contingências, os professores experimentaram novos modelos pedagógicos e novas formas de utilizar os 
tempos de aprendizagem e afirmaram perante a sociedade o seu poder criativo e capacidade de inovar". Para Nóvoa (2020) o que era tido como impossível, transformou-se em poucos dias: diferentes espaços de aprendizagem, sobretudo em casa; diferentes horários de estudo e de trabalho; diferentes métodos pedagógicos, sobretudo através de ensino remoto; e diferentes procedimentos de avaliação. Jabonero (2020, p.59) "elenca as fragilidades estruturais realçadas pela covid-19". Destaca a desigualdade e preocupante distância do mundo digital:penalizando os mais desfavorecidos , é preciso democratizar o acesso à internet e ampliar a conectividade, visto que 0 aprendizado não se restringe ao ambiente escolar formal".

Neste contexto, as tecnología de informação e comunicação foram o suporte para mediar as aprendizagens dos alunos. Ao transformaram ensino e as práticas pedagógicas, os professores criaram situações que envolveram os alunos na sua aprendizagem. As potencialidades pedagógicas da WEB 2.0, pelo surgimento de redes colaborativas de conhecimento, onde assuntos diversos são postos em discussão e o conhecimento é organizado de forma contínua (Carvalho, 2012), exploradas pelo professor, na abordagem dos conteúdos. 0 e-learning, ou educação online, a sua evolução conduziu ao desenvolvimento de Ambientes Virtuais de Aprendizagem (AVA), que têm sido adotados por várias instituições de ensino visando apoiar as necessidades da educação formal, tais como o planeamento, execução, acompanhamento e avaliação do processo de aprendizagem. Atualmente, existem múltiplas plataformas de e-learning ou AVA, que facilitam o processo de gestão da aprendizagem em cursos online e contêm diversos recursos e funcionalidades que permitem a mediatização dos conteúdos de ensino e de aprendizagem e a mediação da comunicação educacional, tais como: textos, animações, gráficos, vídeos, fóruns, chats, quizzes, entre outros ( Silva, 2018 , p. 47).

Com 0 aparecimento progressivo de algumas modalidades de ensino à distância, como 0 e-learning (Electronic Learning), o b-learning (Blended Learning), o m-learning (Mobile Learning) ou o ulearning (Ubiquitous Learning), verificaram-se alterações na forma como decorre o processo de ensino-aprendizagem, na comunicação entre professor e alunos, na interação com os materiais pedagógicos e didáticos, entre muitas outras transformações. Quanto ao $b$-learning, pode-se afirmar que 0 b-learning é a sigla para "blended learning" (Valente, 2014) que pode ser traduzido livremente como aprendizagem híbrida ou mista. É uma modalidade de ensino que utiliza ferramentas tanto do ensino presencial como do ensino a distância.

Corroboramos com a perspetiva da UNESCO, as tecnologias móveis podem ampliar e enriquecer oportunidades, "especialmente telefones celulares e, mais recentemente, tablets são utilizados por alunos e educadores em todo o mundo para acessar informações, racionalizar e simplificar a administração " (UNESC0, 2014,p.7). Assim. a aceleração das tecnologías para as finalidades da escola é uma realidade irrefutável. Porém, é urgente a "necessidade da aceleração de competências digitais na escola" (OCDE, 2019). Embora, "a utilização das tecnologias digitais para comunicar, colaborar, criar e aprender tenha uma relevância inegável na vida profissional de um professor, é essencial na facilitação do processo de aprendizagem", também "são um meio para atingir os resultados de aprendizagem fixados" (Eurydice, 2019).

\section{OBJETIVOS DA INVESTIGAÇÃO}

As escolas portuguesas foram incumbidas de implementar um plano de ensino à distância, com as metodologias adequadas aos recursos disponíveis de cada escola e adaptados aos critérios de avaliação, que deverão ter em atenção os contextos dos alunos. 0 conselho pedagógico de cada escola ou órgão legalmente equivalente, definiria as regras de inscrição de frequência ajustadas às estratégias, recursos e ferramentas disponibilizadas pela escola e por cada aluno. Os professores coletariam evidências da participação dos alunos, usando plataformas virtuais. 


\section{A UTILIZAÇÃO DE TECNOLOGIAS DE SUPORTE AO ENSINO A DISTÂNCIA: PERSPETIVAS dOS PROFESSORES}

Em seguida, em um esforço conjunto, professores, alunos e pais analisaram várias estratégias para se envolver "com um programa educacional e de aprendizagem desafiador" (Palmeirao, 2020).

Compreender como os professores da educação pré-escola e $1^{0}$ ciclo do ensino básico perspetivaram esse esforço conjunto, na supervisão das aprendizagem, tendo em conta as tecnologias adotadas para a mediação pedagógica, durante a pandemia COVID-19.

Com base na problemática apresentada, foram estabelecidos os seguintes objetivos:

Compreender a interação dos professores com os seus alunos;

identificar como foi realizada a monitorizaração das aprendizagens

Perceber como foram avaliadas as aprendizagens.

\section{AMOSTRA E / OU PARTICIPANTES}

Iniciamos o estudo em maio de 2020, tendo em conta a situação de Ensino a Distância, devido ao confinamento obrigatório por causa do COVID-19. Os questionários foram distribuídos de forma online aos professores, por meio da ferramenta Google Forms. Tendo sido enviados por correio eletrónico para os Diretores dos Agrupamentos ${ }^{1}$ de escolas básicas públicas de Portugal continental e dos arquipélagos de Açores e Madeira. Os dados foram recolhidos entre 31 de agosto e 20 de setembro de 2020. Obtivemos 245 resposta tendo sido 170 dos professores do primeiro ciclo e 75 dos professores da educação pré-escolar.

\section{Caracterização dos participantes}

Apresentamos a caracterização dos professores ${ }^{2}$ participantes. A idade dos professores do ensino pré-escolar a maioria situam-se entre os 51-60 anos, numa percentagem de 56\%, seguido 41-50, com uma percentagem de 30,7\% e em menor percentagem, entre os 31-40 com apenas $4 \%$. Com $9,3 \%$ situam-se os mais de 60 anos.

No 1.0 ciclo verificamos que a percentagem mais expressiva $50,6 \%$, se situa entre $41-50$, seguida $51-60$, com uma percentagem de $30,6 \%$ e a menor percentagem de 5,9 , situa-se mais de 60 anos.

Tabela 1. Cataraterização da idade dos professores

\begin{tabular}{|c|c|c|c|c|c|c|}
\hline \multicolumn{2}{c|}{$\begin{array}{c}\text { Idade dos } \\
\text { professores }\end{array}$} & $\begin{array}{c}\text { Entre } \\
\mathbf{3 1 - 4 0}\end{array}$ & $\begin{array}{c}\text { Entre } \\
\mathbf{4 1 - 5 0}\end{array}$ & $\begin{array}{c}\text { Entre } \\
\mathbf{5 1 - 6 0}\end{array}$ & $\begin{array}{c}\text { mais } \\
\text { de 60 }\end{array}$ & \\
\hline \multirow{2}{*}{ Pré-escolar } & Fre & 3 & 23 & 42 & 7 & 75 \\
\cline { 2 - 7 } & $\%$ & $4 \%$ & $30,7 \%$ & $56 \%$ & $9,3 \%$ & $100 \%$ \\
\hline \multirow{2}{*}{$1{ }^{\circ}$ ciclo } & Fre & 22 & 86 & 52 & 10 & 170 \\
\cline { 2 - 7 } & $\%$ & $12,1 \%$ & $50,6 \%$ & 30,6 & $5,9 \%$ & $100 \%$ \\
\hline
\end{tabular}

Quanto ao género (sexo) predominante a lecionar no pré-escolar e no 1ํㅡㄷㅇo do Ensino Básico.

Na educação pré-escolar registaram-se $98,7 \%$ do género feminino e 1,3\% do género masculino.No caso do 1ํㅡㄹ Ciclo, verificamos que $86,5 \%$ são do género feminino e $13,5 \%$ do género masculino.

\section{0 tempo de serviço dos participantes no estudo.}

Os professores na educação pré-escolar, possuíam entre 30 e 40 anos de serviço (44\%); com $(25,3 \%)$ possuíam entre 16 e 25 anos de serviço; porém (18,7\%) tinham entre 26 e 30 anos de serviço, com mais de 40 anos de serviço (5,3\%), como apresenta a tabela 2 . Continuando a analizar a tabela 2, verificamos que os professores do $1^{\circ}$ Ciclo, a maioria situa-se entre 16 e 25 anos de ser- 
viço (44\%); com (21,8\%) possuíam entre 30 e 40 anos de serviço; 12,9\% possuía entre 26 e 30 anos de serviço e 5,9\% possuíam entre 5 e 10 de serviço. Ao cruzarmos os dados da idade com 0 tempo de serviço, constatamos que professores na educação pré-escolar, a percentagem mais alta (44\%) situa-se entre 30 e 40 anos de serviço e na idade verificamos que a maioria (56\%) situa-se nos 51e 60 anos. Enquanto no primeiro ciclo os professores são um pouco mais jovens, a percentagem mais alta (44\%) situa-se entre 16 e 25 e verifica-se 50,6\% na idade compreendida entre 41 e 50 anos.

Tabela 2. Tempo de serviço docente

\begin{tabular}{|c|c|c|c|c|c|c|c|c|}
\hline \multicolumn{2}{|l|}{$\begin{array}{l}\text { Tempo de } \\
\text { serviço }\end{array}$} & $\begin{array}{c}\text { menos } \\
\text { de 5 } \\
\text { anos }\end{array}$ & $\begin{array}{c}\text { Entre } \\
\mathbf{5 - 1 0}\end{array}$ & $\begin{array}{c}\text { Entre } \\
\mathbf{1 1 - 1 5}\end{array}$ & $\begin{array}{c}\text { Entre } \\
\mathbf{1 6 - 2 5}\end{array}$ & $\begin{array}{c}\text { Entre } \\
\mathbf{2 6 - 3 0}\end{array}$ & $\begin{array}{c}\text { Entre } \\
\mathbf{3 0 - 4 0}\end{array}$ & $\begin{array}{c}\text { mais } \\
\text { de 40 }\end{array}$ \\
\hline \multirow{2}{*}{$\begin{array}{c}\text { Pré- } \\
\text { escolar }\end{array}$} & $\%$ & 1 & 1 & 3 & 19 & 14 & 33 & 4 \\
\hline \multirow{2}{*}{$1 .^{\mathbf{0}}$ ciclo } & Fre & 1,3 & 1,3 & $4 \%$ & 25,3 & 18,7 & $44 \%$ & 5,3 \\
\cline { 2 - 10 } & $\%$ & 1,2 & 5,9 & 11,8 & $44 \%$ & 12,9 & 21,8 & 2,4 \\
\hline
\end{tabular}

Quanto à formação académica, tal como podemos observar na tabela 3, a licenciatura é a habilitação dominante na educação pré-escolar $(69,3 \%)$ e $(67,6)$ no 1.ำ ciclo, seguindo-se os profissionais com Pós graduação com $13,3 \%$ na educação pré-escolar e 16,5 no 1.․․ ciclo. Por último, 0 Mestrado regista $6,7 \%$ na educação pré-escolar e $12,4 \%$ no $1 . .0$ ciclo. Existem dois elementos que indicaram habilitação de doutoramento sendo um em cada ciclo e 12 intervenientes com habilitações académicas correspondentes ao bacharelato; sete na educação pré-escolar e cinco no 1.. ciclo.

Tabela 3. Habilitações académicas

\begin{tabular}{|c|c|c|c|c|c|c|c|}
\hline \multicolumn{2}{|c|}{$\begin{array}{l}\text { Habilitações } \\
\text { académicas }\end{array}$} & \multirow{2}{*}{$\begin{array}{l}\text { Bacharelat } \\
\text { o } \\
7\end{array}$} & \multirow{2}{*}{$\begin{array}{c}\text { Licenciatu } \\
\text { ra } \\
52\end{array}$} & \multirow{2}{*}{$\begin{array}{c}\begin{array}{c}\text { Pós } \\
\text { graduação }\end{array} \\
10\end{array}$} & \multirow{2}{*}{$\begin{array}{c}\begin{array}{c}\text { Mestra } \\
\text { do }\end{array} \\
5\end{array}$} & \multirow{2}{*}{\begin{tabular}{|c|}
$\begin{array}{c}\text { Doutoramen } \\
\text { to }\end{array}$ \\
1
\end{tabular}} & \\
\hline \multirow{2}{*}{$\begin{array}{l}\text { Pré- } \\
\text { escolar }\end{array}$} & $\begin{array}{c}\mathrm{Fr} \\
\mathrm{e}\end{array}$ & & & & & & 75 \\
\hline & $\%$ & 9,3 & 69,3 & 13,3 & 6,7 & 1,3 & $\begin{array}{c}10 \\
0\end{array}$ \\
\hline \multirow[t]{2}{*}{ 1. ${ }^{\circ}$ Ciclo } & $\begin{array}{c}\mathrm{Fr} \\
\mathrm{e}\end{array}$ & 5 & 115 & 28 & 21 & 1 & $\begin{array}{c}17 \\
0\end{array}$ \\
\hline & $\%$ & 2,9 & 67,6 & 16,5 & 12,4 & 0,6 & $\begin{array}{c}10 \\
0\end{array}$ \\
\hline
\end{tabular}

\section{METODOLOGIA E / OU INSTRUMENTOS UTILIZADOS}

Neste estudo, procurámos abarcar a compreensão dos fenómenos investigados no contexto em que ocorrem, recorremos a uma metodologia de natureza quantitativa que constitui um processo sistemático de recolha de dados observáveis e quantificáveis sobre um conjunto alargado de pessoas, relativos a um certo número de questões pré-determinadas (Coutinho, 2014). A investigação quantitativa é centrada "na análise de factos e fenómenos observáveis e na medição/avaliação de variáveis comportamentais e/ou sócio afetivas, passíveis de serem medidas, comparadas e/ou relacionadas" (Coutinho, 2014). 


\section{A UTILIZAÇÃO DE TECNOLOGIAS DE SUPORTE AO ENSINO A DISTÂNCIA: PERSPETIVAS dOS PROFESSORES}

Elaborámos 0 inquérito por questionário (Ghiglione \& Matalon, 2001; Hill \& Hill, 2009) com seis dimensões: Perceções dos professores sobre 0 Ensino a distância, com 9 itens de resposta fechada; condições de operacionalização o Ensino a distância , com 26 itens de resposta fechada; a monitorização, com 25 itens de resposta fechada; avaliação, com 9 itens de resposta fechada; constrangimentos e aspectos positivos, com 1 item de resposta aberta e 00 Ensino a distância e as expressões, com 5 itens de resposta fechada e 1 item de resposta aberta.

Neste artigo vamos analisar apenas duas dimensões, a saber: Perceções dos professores sobre como foram monitorizadas as aprendizagens e a compreender como foram avaliadas .

A construção desta base de dados gerou a possibilidade de quantificar uma multiplicidade de dados e proceder a estadística descritiva com aplicação do software SPSS.

\section{RESULTADOS ALCANÇADOS}

Na primeira dimensão, pretendemos analisar a perspetiva dos professores sobre a interação ou ausência de interação dos professores com os alunos do 1. ciclo. Tal como podemos observar no gráfico 1 . Os nossos professores $(n=64 ; 37,6 \%)^{3}$, referem a ausência de interação entre 1 a 2 alunos; com ( $n=42 ; 24,7 \%$,) apontam a ausência de interação entre 3 a 5 alunos; mas ( $n=17 ; 10 \%)$ interagiram com todos os alunos; a ausência de interação entre 6 a 9 os dados referem $(n=13 ; 7,65 \%)$ e $8,24 \%$ não interagiu com mais de 10 alunos.

\section{Gráfico 1. Ausência de Interação no 1.ํㅗ ciclo}

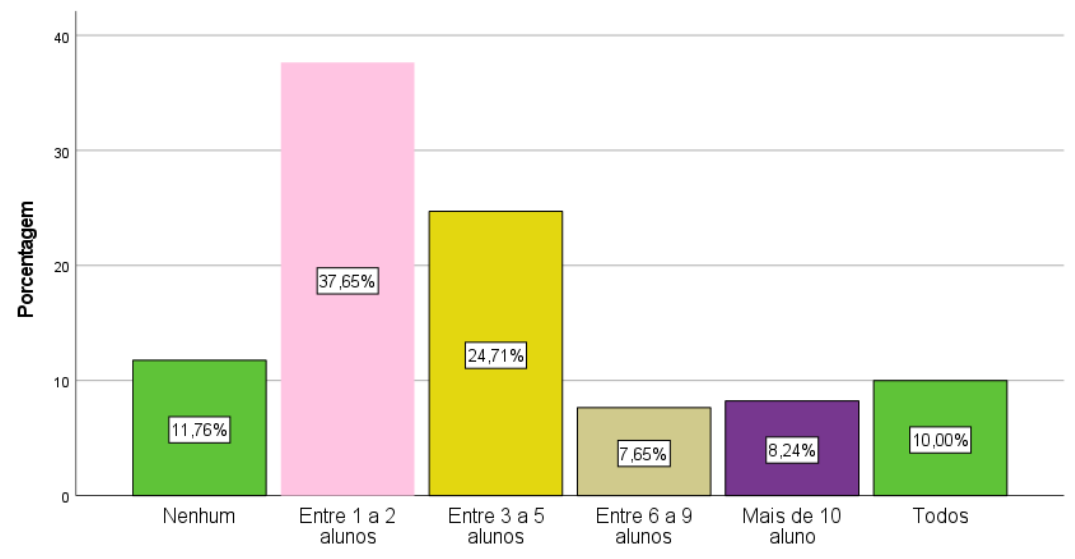

Relativamente ao pré-escolar. Como podemos observar no gráfico 2. Com ( $n=23 ; 31,1 \%)$ dos professores referem a ausência de interação entre 1 a 2 alunos; com a frequência ( $n=26 ; 35,1 \%)$ referem a ausência de interação entre 3 a 5 alunos; Corresponde a ( $n=8 ; 10,8 \%$ )a ausência de interação entre 6 a 9 alunos; interagiram todos os alunos $8,1 \%$. 
Gráfico 2. Ausência de interação no pré-escolar

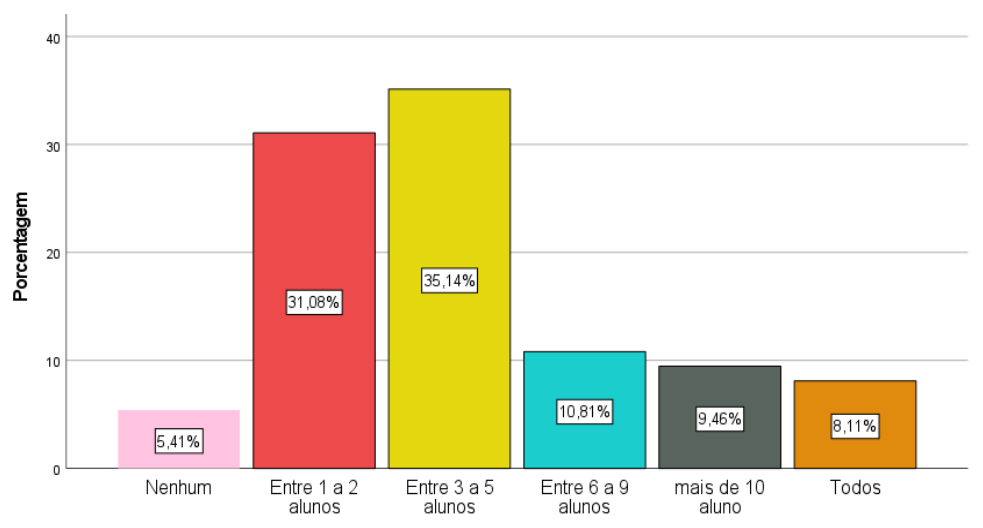

A Perceção dos professores relativamente à interação e falta de interação com os alunos, deveu-se em parte à ausência de recursos tecnológicos disponíveis nos agregados familiares de alguns alunos.

Analisámos os recursos tecnológicos existentes no agregado familiar relativamente ao 1.ำ ciclo. Como podemos observar no gráfico 3. Na perspetiva dos professores deste estudo refere: $59,5 \%$ mencionam que quase todos os alunos tinham computador; $27,6 \%$ poucos possuíam computador e apenas $10 \%$ indicam que todos os alunos tinham computador. A estatistica descritiva, a média dos alunos que possuiam computador situa-se 2,17 e 0 desvio padrão ,606.

Verificamos os dados relativamente à internet $25,3 \%$ tinham internet no agregado familiar, $46,5 \%$ quase todos tinham internet e apenas $10 \%$ poucos alunos tinham internet. Assim, a média estatistica da internet no agregado familiar, situa-se 1,56 e 0 desvio padrão, 870 .

Gráfico 3.Recursos tecnológicos no agregado familiar

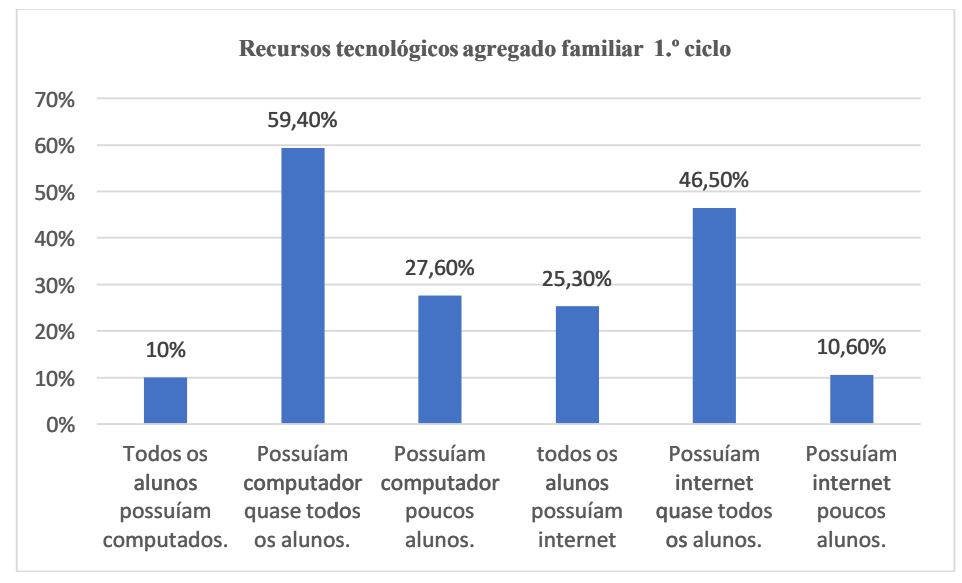




\section{A UTILIZAÇÃO DE TECNOLOGIAS DE SUPORTE AO ENSINO A DISTÂNCIA: PERSPETIVAS DOS PROFESSORES}

Passámos agora à análise dos recursos tecnológicos existentes no agregado familiar relativamente ao pré-escolar. Pela leitura do gráfico 4, verificamos que $61,3 \%$ perspetivaram que quase todos os alunos tinham computador; $22,7 \%$ refere que poucos tinham computador e somente $8 \%$ referem que todos tinham computador. No que concerne à internet $49,3 \%$ apontam que quase todos tinham internet, 22,7\% todos tinham internet e apenas $4 \%$ menciona que poucos tinham internet. No global a média situa-se 2,37 e 0 desvio padrão ,927.

Gráfico 4.Recursos tecnológicos no agregado familiar

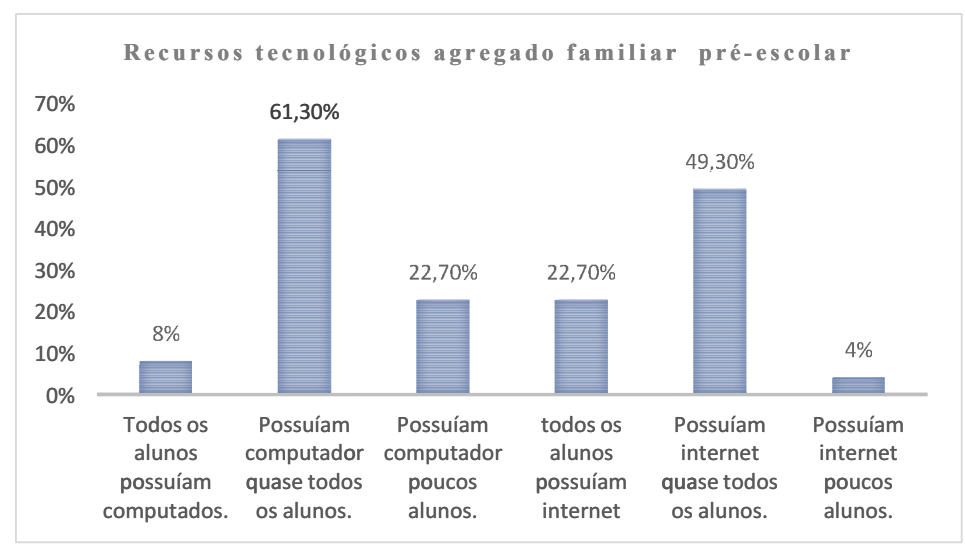

Relativamente à variável, "consideras ter interagido com regularidade com os seus alunos". Observamos os dados da tabela 4 , verificamos que no 1.. ciclo $(n=131 ; 77,1 \%)$ corresponde ao rótulo do valor da variável sempre. Com $(n=36 ; 21,2 \%)$ corresponde ao rótulo quase sempre; e apenas $(n=3 ; 1,8 \%)$ refere rótulo do valor da variável raramente.

Tabela 4. Interagir com os alunos regularmente Interagir com os alunos regularmente $-1 .^{\circ}$ ciclo

\begin{tabular}{ll|r|r|r|r} 
& & & Percentagem & \multicolumn{2}{c}{$\begin{array}{c}\text { Percentagem } \\
\text { acumulativa }\end{array}$} \\
\hline Válido & Sequência & Percentagem & válida & 77,1 \\
\cline { 2 - 6 } & 131 & 77,1 & 77,1 & 98,2 \\
\cline { 2 - 6 } & Quase sempre & 36 & 21,2 & 21,2 & 100,0 \\
\hline Raramente & 3 & 1,8 & 1,8 & \\
\cline { 2 - 6 } & Total & 170 & 100,0 & 100,0 & \\
\hline
\end{tabular}

Observamos na tabela 5 , os dados relativos ao pré-escolar que nos indicam ( $n=51 ; 68,9 \%$ ) corresponde ao rótulo do valor da variável sempre. Seguido $(n=20 ; 26,7 \%)$ corresponde ao rótulo quase sempre; e apenas $(n=3 ; 4 \%)$ refere rótulo do valor da variável raramente e 1 omisso. Relativamente à media 1,35 a mediana 10 desvio padrão,560 . 
Tabela 5. Interagir com os alunos regularmente

Interagir com os alunos regularmente na educação - pré-escolar

\begin{tabular}{llr|r|rr|r} 
& Frequência & $\begin{array}{c}\text { Percentage } \\
\mathrm{m}\end{array}$ & $\begin{array}{l}\text { Percentagem } \\
\text { válida }\end{array}$ & $\begin{array}{c}\text { Percentagem } \\
\text { acumulativa }\end{array}$ \\
\hline Válido & Sempre & 51 & 68,0 & 68,9 & 68,9 \\
\cline { 2 - 7 } & $\begin{array}{l}\text { Quase } \\
\text { sempre }\end{array}$ & 20 & 26,7 & 27,0 & 95,9 \\
\cline { 2 - 7 } & Raramente & 3 & 4,0 & 4,1 & 100,0 \\
\cline { 2 - 7 } & Total & 74 & 98,7 & 100,0 & \\
\hline Omisso & Sistema & 1 & 1,3 & & \\
\hline Total & & 75 & 100,0 & & \\
\hline
\end{tabular}

\section{Instrumentos utilizados}

Observamos no gráfico 5, No 1.ำ ciclo, de acordo com os dados obtidos, no âmbito destes instrumentos, o mais usada foi o manual adotado com ( $n=139 ; 81,8 \%)$. Seguem-se as plataformas educativas, com $(n=133 ; 78,2 \%)$ dos professores consideram utilizá-las. Com $(n=129 ; 75,9 \%)$ referem os vídeos. As fichas formativas e PowerPoints obtêm os mesmos resultados ( $n=114 ; 67,1 \%)$. Estes dados revelam que os professores deste estudo usaram com alguma regularidade estes instrumentos para orientar os alunos na aprendizagem. Com ( $n=94 ; 55,3 \%)$ estão os jogos didácticos; as animações $(n=98 ; 57,6 \%)$. Se juntarmos as duas opções verificamos que mais cinquenta por cento dos professores utilizaram estes instrumentos $55,3 \%$ e $57,6 \%$.

Observamos também o resultado Kahoot com $(n=30 ; 17,6 \%)$ e o Padlet com ( $n=19 ; 11 \%)$ verificamos que os professores deste estudo usaram com menos frequência estas plataformas.

Gráfico 5. Instrumentos utilizados no 1.․ㅜ ciclo

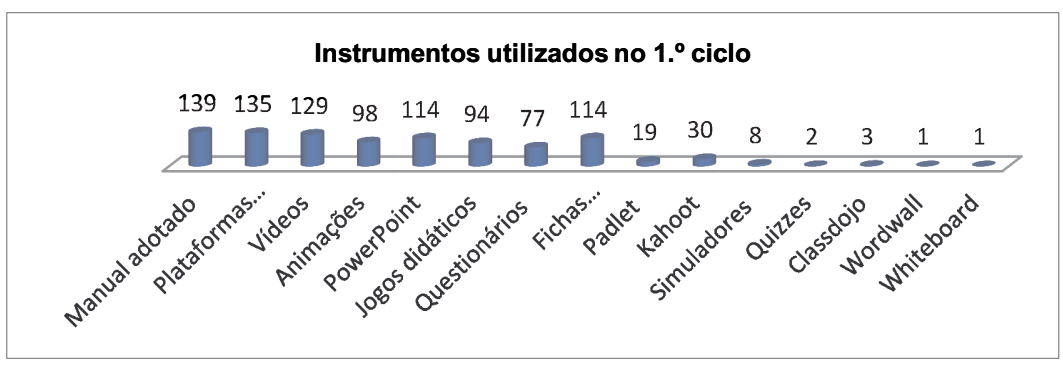

Relativamente ao pré-escolar os professores inquiridos referem que os instrumentos mais utilizados foram os vídeos com $(n=60 ; 80 \%)$. Tal como podemos observar no gráfico 6 . Continuando a observar o gráfico, confirmamos que os jogos didácticos apresentam os resultados ( $n=56 ; 74,7 \%$ ). Corroborando com a perspetiva de (Andrade, 2012) quando refere "os jogos digitais são passíveis de desenvolver aprendizagens em diversos aspectos, tais como: comportamentos, pela imitação, feedback e prática; criatividade, pelo jogo e pela ação; fatos, pela associação, pela memorização (....)".

As animações apresentam o resultado de $(n=46 ; 61,3 \%)$; os PowerPoints com $(n=39 ; 52 \%)$ e as plataformas educativas com $(n=22 ; 29,3 \%)$. 


\section{A UTILIZAÇÃO DE TECNOLOGIAS DE SUPORTE AO ENSINO A DISTÂNCIA: PERSPETIVAS DOS PROFESSORES}

Gráfico 6. Instrumentos utilizados na educação pré-escolar

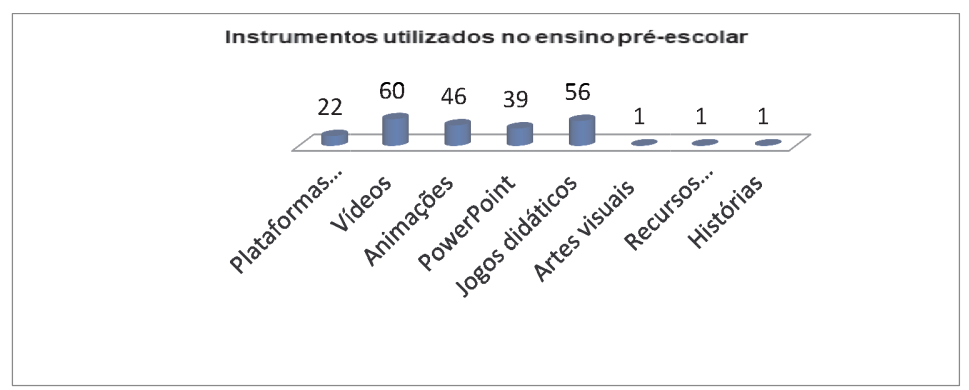

\section{Recolha de evidência avaliativas}

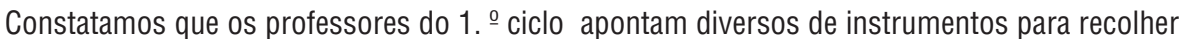
informação, a saber: 0 trabalho individual $(n=152 ; 89,4 \%)$; seguido $(n=132 ; 77,6 \%)$ das fichas; das fotos $(n=108 ; 63,5 \%)$. Os questionários obtêm também resultados consideráveis ( $n=88 ; 51,8 \%)$; os vídeos $(n=71 ; 41,8 \%)$. Constatamos que o portefólio e as composições alcançaram os mesmos resultados $(n=33 ; 19,4 \%)$. Enquanto 0 trabalho de grupo apresenta um resultado inferior( $n=19$; $11,2 \%)$.

Gráfico 7. Recolha da informação 1.․ㅗ ciclo

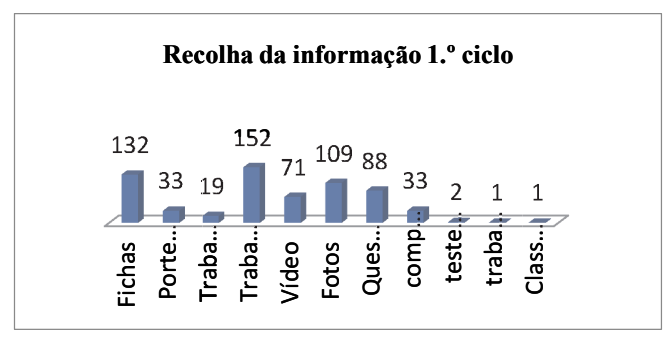

Quanto aos professores da educação pré-escolar verificamos as evidências mais utilizadas foram: as fotos com a frequência e percentagem mais alta ( $n=62 ; 82,7 \%)$; seguida dos vídeos $(n=48 ; 64 \%)$ e do trabalho individual atingiu frequência $(n=45 ; 60 \%)$. 0 portefólio registou menor utilização ( $n=12 ; 16 \%)$, como sendo pouco utilizado para recolher informação.

Gráfico 8. Recolha da informação no ensino pré-escolar

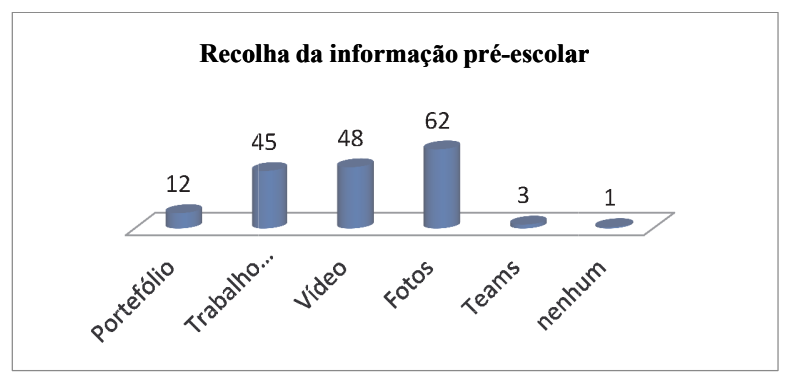




\section{DISCUSSÃO}

Os dados referentes aos professores que participaram deste estudo permite-nos tecer algumas reflexões de acordo com a sua larga experiência profissional e práticas escolares. Constatamos que os professores do no 1.ำ ciclo são um pouco mais jovens do que os professores da educação préescolar. 0 género predominante neste estudo é o sexo feminino, estes resultados estão em conformidade com publicação da Direção Geral de Estastistica da Educação e Ciência, na revista "Educação em Números: Portugal 2018” (DGEEC 2018 p.59).

Confirmamos as dificuldade sentidas pelos professores na interação com os alunos ( $1 . \stackrel{\circ}{ }$ ciclo e pré-escolar), dado que, apenas $18 \%$ referem que conseguiu interagir com todos os seus alunos. Corroboramos com o problema da falta de recursos tecnológico no ambiente familiar, como nos comprovam a estatistica descritiva, relativamente ao 1.0 ciclo, verificamos que a média dos alunos que possuiam computador situa-se 2,17 e o desvio padrão ,606 e dos alunos que possuiem internet no agregado familiar, situa-se 1,56 e 0 desvio padrão,870. No pré-escolar, a média situase em 2,37 e 0 desvio padrão ,927. As desigualdades preocupantes do digital postas a descoberto com esta pandemia, não foi possível 0 ensino à distância chegar a todos os alunos. 0 ensino a distância aumenta a dificuldade de chegar aos alunos que não têm acesso a computador/tablet/internet como nos refere (Alves, 2020).

Nas dinâmicas de trabalho os professores adotaram as redes sociais e aplicações usadas até então para fins pessoais e transformaram-se em novas ferramentas de trabalho pedagógico, no sentido de encontrar as estratégias mais eficazes na monitorização das aprendizagens. Assim, os instrumentos pedagógica mais utilizados pelos professores dos diversos ciclos foram: os vídeos; PowerPoint's ; o manual adotado; Plataformas (Zoom, Skype, Teams, Classroom, Moodle, Escola virtual, etwinning ,Kan academy...); as fichas sumativas e formativas; os questionários; jogos didáticos; Kahoot e Padlet. 0 Kahoot e o Socrative surgem como plataformas de gamificação que podem ser facilmente integradas às atividades de sala de aula. Essas ferramentas possibilitam ao professor a criação de quizzes, questionários, dentre outras tarefas que favorecem a protagonização do aluno, sua motivação e feedback instantâneo. Esses aplicativos favorecem a motivação, e a avaliação da aprendizagem por meio de jogo e exercício lógico. (Carvalho, L.A. et al. 2018).

Quanto aos procedimentos e técnicas de avaliação, para recolha da informaç̧ão necessária ao apoio às aprendizagens. Reportando-nos às evidências avaliativas que os professores mencionaram ter utilizado, esta foi diversificada nomeadamente: trabalho individual; fichas; questionários; fotos; vídeos; portefólio; Ensaio/composições /reflexão crítica e outros. Admitimos a impossibilidade de replicar as práticas de avaliação habitual, os célebres dois testes escritas por período, da velha gramática. (Alves, 2020).

\section{CONCLUSÕES}

A pandemia trouxe para casa, esta explosão súbita do ensino a distância levou os professores a encontrar diversas soluções inovadoras como pudemos constatar no estudo. Apesar das dificuldades sentidas por alguns professores em transformar as modalidades de ensino aprendizagem. Creio que ninguém pode ficar indiferente aos atuais desafios e tendências, as modalidades online e presencial estão conectadas para fornecer experiências de aprendizagem integrada. Os professores socorrendo-se de dispositivos móveis, redes sociais, plataformas virtuais, com recurso à internet. A pandemia acelerou a urgência do digital na educação, porque evidenciou as desigualdades entre os alunos com e sem computador, com e sem conectividade. 0 ensino a distância abriu novos horizontes e trouxe novas formas de aprender à escola. Obrigou à mudança de práticas pedagógicas, independentemente da modalidade presencial e a distância. No entanto, a tecnologia deve ser adequada aos conteúdos disciplinares, ao público-alvo e às competências a serem trabalhadas na 
prática pedagógica. Assim, cabe aos professores utilizar todos os recursos educativos digitais, de desdobrá-los e desenvolvê-los a seu favor.

\section{AGRADECIMENTOS}

Este estudo teve o financiamento do CIEC (Centro de Investigação em Estudos da Criança), pelo Projeto Estratégico UID/CED/00317/2013, através dos Fundos Nacionais da FCT (Fundação para a Ciência e a Tecnologia), cofinanciado pelo Fundo Europeu de Desenvolvimento Regional (FEDER) através do COMPETE 2020 - Programa Operacional Competitividade e Internacionalização (POCI) com a referência POCl-01-0145-FEDER-007562.

\section{REFERENCIAS BIBLIOGRÁFICAS}

Alves, J. (2020). Entre o caos e a esperança. In Alves, J. \& Cabral. Ensinar e aprender em tempo de COVID 19: entre o caos e a redenção. Universidade Católica Portuguesa. Porto. Consultado em 20 de agosto 2020, disponível em:https://www.dge.mec.pt/noticias/e-book-ensinar-e-aprenderem-tempo-de-covid-19-entre-o-caos-e-redencao

Andrade, A. (2012). Jogos e simuladores. Porto. Consultado em 01 de outubro de 2019, disponível em: http://www.slideshare.net/aandradevalente/jogos-e-simuladores

Carvalho, A. (2012). Web 2.0, educação a distância e 0 conceito de aprendizagem colaborativa na formação de professores. Consultada em 10 abril de 2012, disponívelem:http://anabeatrizgomes.pro.br/moodle/file.php/1/ARTIGOWEB2.0.pdf

Costa, J. (2021) As escolas fecharam, e a educação não ficou suspensa. Revista Saber \& Educar 29/2021: "Escolas encerradas: que educação em tempos de Covid-19?". Disponível em http://revista.esepf.pt/index.php/sabereducar

Coutinho, C. (2014). Metodologia de investigação em ciências sociais e humanas: Teoria e prática. Lisboa: Almedina.

Direção-Geral de Estatísticas da Educação e Ciência (DGEEC). (2018). Educação em Números Portugal 2018. Lisboa: Direção-Geral de Estatísticas da Educação e Ciência.

OCDE, 2019b. TALIS 2018 Results (Volume I): Teachers and School Leaders as Lifelong Learners, TALIS. [Online] Consultada em 20 de março de 2021 Disponível em: http://doi.org/10.1787/1d0bc92a-en.

Comissão Europeia/EACEA/Eurydice, 2019. A Educação Digital nas Escolas da Europa. Relatório Eurydice. Luxemburgo: Serviço das Publicações da União Europeia.

Figueiredo, A. (2020). Os Equívocos da Educação à Distância. Sinal Aberto. Edição de 20 de junho. Ghiglione, R., \& Matalon, B. (2001). O Inquérito. Teoria e Prática. Oeiras: Celta

Hill, M., \& hill , A. (2009). Investigação por Questionário. Lisboa: Edições Sílabo.

Nóvoa, A. A pandemia de Covid-19 e o futuro da Educação. Revista Com Censo: Estudos Educacionais do Distrito Federal, [S.I.], (7) 3. 8-12, ago. 2020. ISSN 2359-2494. Disponível em: <http://periodicos.se.df.gov.br/index.php/comcenso/article/view/905>

Palmeirão, C. (2020). Digitais por obrigação. In Alves, J. \& Cabral, I. Ensinar e aprender em tempo de COVID 19: entre o caos e a redenção. Universidade Católica Portuguesa. Porto .Consultado em 20 de agosto 2020, disponível em:https://www.dge.mec.pt/noticias/e-book-ensinar-e-aprender-em-tempo-de-covid-19-entre-0-caos-e-redencao

Silva, V. G. (2018) Dos Dispositivos Móveis à Aprendizagem Ubíqua - Da Usabilidade Técnica à Usabilidade Pedagógica. Tese de Doutoramento. Braga. Universidade do Minho. Consultado em 20 de março de 2020, disponível em: http://repositorium.sdum.uminho.pt/handle/1822/60664 Valente, J. A. (2014). Blended learning e as mudanças no ensino superior: a proposta da sala de aula 
invertida. Educ. rev. [online]. 2014, n.spe4, pp.79-97. ISSN 0104-4060. http://dx.doi.org/10.1590/0104-4060.38645

Verdasca, J. (2021). A escola em tempos de pandemia: narrativas de professores. Revista Saber \& Educar 29/2021: “Escolas encerradas: que educação em tempos de Covid-19?".Disponível em http://revista.esepf.pt/index.php/sabereducar

Jabonero, M. (2020) Covid-19 e as fragilidades estruturais de uma "normalidade" excludente. In Kalache, A. Trilhas da longevidade [livro eletrônico] : desafios diante da pandemia / Alexandre Kalache. — Goiânia, GO : Inteligência Educacional, 2020. — (Série especial de webinários internacionais) PDF. https://oei.int/downloads/disk/

10 agrupamento de escolas é uma unidade organizacional do sistema educativo de Portugal, dotada de órgãos próprios de administração e gestão, constituída por estabelecimentos de educação pré-escolar e de um ou mais níveis e ciclos de ensino, a partir de um projecto pedagógico comum

${ }^{2}$ Com a frequência (Fre) e a percentagem(\%)

3 frequência e percentagem 
